\title{
Hablando del patrimonio cultural: historia oral escolar y fuentes orales en la enseñanza patrimonial
}

\author{
TALKING ABOUT CULTURAL PATRIMONY: SCHOOL ORAL HISTORY AND ORAL SOURCES \\ IN PATRIMONIAL TEACHING \\ FALANDO DO PATRIMÔNIO CULTURAL: PROJETOS ESCOLARES DE HISTÓRIA ORAL E \\ FONTES ORAIS NO EDUCAÇÃO PATRIMONIAL
}

Oscar Eduardo Rueda Pimiento* / oscar.rueda@upb.edu.co

\begin{abstract}
Resumen
La educación patrimonial enfrenta a los educadores a diversos retos, debido a la acelerada desaparición de muchos escenarios del pasado en las ciudades de hoy, y a la responsabilidad de generar conciencia patrimonial en un mundo que, descrito por Pierre Nora, es "presa de la inmediatez". Circunstancia que exige encontrar estrategias metodológicas efectivas para enseñar estos contenidos asociados a la formación ciudadana, las Ciencias Sociales e Historia. Al respecto, la Historia oral escolar y las fuentes orales ofrecen varias alternativas. El siguiente trabajo explora algunas de ellas.

Abstract

Patrimonial education confronts teachers to various challenges due to the quick disappearance of many past scenarios in today's cities and the responsibility of generating patrimonial consciousness in a world described by Pierre Nora as "Prey of immediacy" This circumstance requires finding effective methodological strategies to teach the contents of Civic Education, Social Sciences and History. To this respect, School Oral History and oral sources offer various alternatives and the following work explores some of them.

\section{Resumo}

A educação patrimonial confronta aos professores a vários desafíos devido ao acelerado desaparecimento de muitos cenários do passado nas cidades de hoje e a responsabilidade de de geraro conhecimento do património em um mundo descrito por Pierre Nora como "presa do imediato." Circunstância que requer encontrar estratégias metodológicas efetivas com a finalidade de ensinar esses conteúdos de Educação Cívica, Ciências Sociais e História. Neste sentido, a escola de história oral e fontes orais oferecem várias alternativas. $\mathrm{O}$ artigo seguinte explora alguns deles.
\end{abstract}

\section{Palabras clave}

Educación patrimonial, historia oral escolar, memoria, patrimonio cultural, pedagogía.

\section{Key words}

Patrimonial education, school oral history, memory, cultural patrimony and pedagogy.

\section{Palavras-chave}

Educação patrimonial, projetos de história oral, memória, patrimônio cultural e pedagogia

Fecha de recepción: 30 de junio de 2014 / Fecha de aceptación: 31 de octubre de 2014

* Docente asistente en la Universidad Pontificia Bolivariana (sede Bucaramanga), Magíster en Pedagogía de la Universidad Industrial de Santander. 


\section{Introducción}

El proceso de aprender, enseñar y difundir el patrimonio cultural obliga, en el contexto educativo actual, al despliegue de novedosas estrategias pedagógicas en las que dicho proceso de aprendizaje trascienda el binomio profesor-estudiante, texto-contenido y aula de clase-enseñanza patrimonial. Afortunadamente, se vislumbran en el mundo de hoy nuevas fuentes y espacios desde los cuales puede resultar más atractivo para los jóvenes "aprehender" y tener un contacto directo con nuestro patrimonio; aspectos clave cuando se promueve la vinculación del patrimonio cultural, y sus diversas manifestaciones, a la enseñanza de las ciencias sociales.

Estos intentos por introducir ciertos elementos de las pedagogías activas en la enseñanza patrimonial, son a menudo criticados debido a la escasa fundamentación teórica y a la ausencia de memoria de los mismos, lo cual, a juicio de algunos expertos (Vega \& Castaño, 1999 y Acuña, 2010), es necesario para establecer precedentes en la discusión epistemológica acerca de sus posibilidades. Mientras esto cambia, la introducción de temas relacionados con nuestro patrimonio cultural en el aula, permanece en muchos casos sometida a lo que Estanislao Zuleta, en entrevista con Hernán Suarez (1995), critica como la enseñanza en "leyenda patria", es decir, una forma de enseñar la historia en la que el acontecimiento historiográfico y sus protagonistas acaparan por completo la narración e interpretación de la historia nacional (Vargas, Acosta y Sánchez, 2013).

Circunstancia lamentable, especialmente en el caso de la ciudad, donde la educación patrimonial enfrenta a los educadores a otros retos, como la acelerada desaparición de muchos escenarios del pasado, bajo la avalancha de la gentrificación como estrategia de márquetin urbano, y la responsabilidad de generar conciencia patrimonial en lo que Pierre Nora, en entrevista con Luisa Corradini (2006), afirma es un mundo "presa de la inmediatez", donde el pasado se encuentra en permanente peligro de convertirse, gracias a su olvido, en "imágenes borradas por una modernidad de aparador" (Reguillo, 2008, p. 67). La situación actual del patrimonio en nuestras ciudades es muestra de estas circunstancias y, además, de su desvinculación de los procesos de construcción de la identidad. Al respecto, los ejemplos abundan.

Así, actualmente la enseñanza patrimonial necesita de una verdadera revolución copernicana (siguiendo al formula de Philippe Meirieu, 1998) a partir de la cual sea posible "restaurar" el significado social del patrimonio, origen de nuestro vínculo afectivo y biográfico con sus manifestaciones. Esto exige encontrar estrategias metodológicas efectivas para enseñar estos contenidos asociados a la formación ciudadana, las ciencias sociales y la historia.

Con el actual trabajo se pretende establecer precedentes en la discusión epistemológica acerca de las posibilidades para hacer que esto sea posible $y$, a la vez, hacer frente desde la escuela a las tensiones entre las políticas propuestas para el manejo y preservación del patrimonio cultural y la falta de "conciencia patrimonial" (Bardavio y Gonzales, 1993) entre algunos grupos sociales, en especial entre los jóvenes. Este último aspecto es evidente por las condiciones actuales de deterioro y desconocimiento de nuestro patrimonio. Al tiempo, se busca responder a la escasa investigación nacional e identificar estrategias y posibilidades ofrecidas por la historia oral escolar en la enseñanza dentro de contextos urbanos y, específicamente, favorecer procesos de reconocimiento y valoración del patrimonio cultural (Rueda, 2013).

En 1997, el libro Déjenos hablar inicia lamentando que en Colombia la historia oral escolar no forme parte de los procesos de enseñanza de la historia dentro del aula de clase, y hoy, 17 años después, esta situación no parece cambiar. Circunstancia desconcertante, principalmente por la enorme aceptación que tiene la historia oral en la educación y la actual preocupación por encontrar alternativas que supongan superar la enseñanza tradicional de la historia, esto es, aquella en donde hay quienes entregan la información y otros que sólo escuchan (Bardavio y Gonzales, 2003; Santiago, 1996).

Como en otros casos, el verdadero reto es enfrentar el aparente desinterés que por largo tiempo ha separado a la historia oral de las disciplinas que estudian las sociedades que existieron en el pasado, de sus formas 
de vida cotidiana y de los conflictos cotidianos entre las distintas clases y grupos sociales; aspectos que pueden resultar emocionalmente más cercanos a la experiencias de los estudiantes y, por lo tanto, mucho más interesantes (Vega y Castaño, 1999, p. 29).

\section{Patrimonio cultural. Memoria, historia y ciudad}

La cartografía oficial representa los territorios habitados por una cultura. Es el objeto tradicional de estudio en la ciudad y permite pensarla como contexto estable y, en apariencia, uniforme; está conformado por la sociopolítica y legitimado a partir de principios como la seguridad y la presencia institucional. Contrario a ella, la cartografía social se manifiesta en las prácticas y usos cotidianos en el momento de ocupar los espacios, en la creencias (ritos y mitologías) que se materializan con el tiempo en imaginarios cartográficos sobre el paisaje y sus códigos estéticos, etc.; es decir, según la fórmula de Federico Medina (2003), casi todos los rasgos que estudian los antropólogos se encuentran marcados significativamente.

El patrimonio cultural, al menos en su concepción tradicional, depende de los principios con mayor estabilidad ${ }^{1}$. Situación que enfrenta a los encargados de su gestión a algunos dilemas; por ejemplo, quienes están encargados de planificar su recuperación y conservación, se enfrentan con modalidades de la espacialidad urbana que conciben el patrimonio como "resistencias" de un pasado tenaz, compuesto a menudo por antiguos edificios y viviendas, ruinas de este pasado que desfiguran estéticamente a la ciudad modernista y homogénea, mientras pretenden promover su reconocimiento como bienes de interés "nacional" y "tesoros" cuyo rescate es necesario; modalidad esta que, según Michel de Certeau y Lucen Girard (1999), es el fundamento de la pedagogía historicista y legitimada por las políticas museológicas.

Similar es la situación para los responsables de educar a los públicos, que se debaten entre la normativa vigente (tanto estatal como autonómica), que marca entre sus objetivos generales la necesidad de que los alumnos conozcan su patrimonio cultural, reconociendo así

1 Ver Figura 1. Cartografía social y patrimonio Cultural. su interés cultural, político, social y educativo, y el hecho de que advierten, según su experiencia, el poco conocimiento y estima que los jóvenes tienen por el mismo, considerándolo reflejo de la "cultura de élite", a "lo monumental", "lo antiguo" y "lo histórico", según explica Manuela Fernández Casildo (2008). Aspectos que intervienen para convertir el patrimonio en un elementos abstracto que muchos respetan pero que muy pocos conocen (Fontal, 2003).

Figura 1. Cartografía social y Patrimonio Cultural

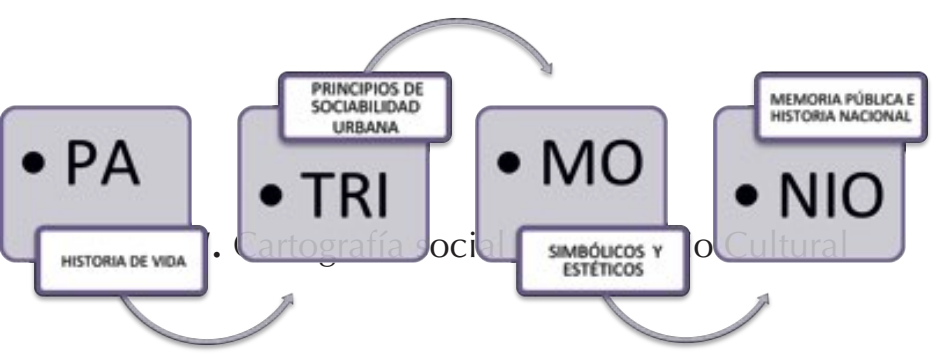

Por años, la gestión del patrimonio en el Departamento de Santander consagró lo que algunos expertos consideran el imaginario civilista del patrimonio, gobernado por manifestaciones artísticas, monumentales y arquitectónicas empleadas para resaltar las virtudes y valores "idéales" de la sociedad (Martínez, 2009). Sin embargo, en los últimos años este modelo ha convivido con diferentes propuestas de activación del patrimonio que, además de reconocer que éste debe tener una función social, exigen su transformación en un recurso económico rentable y buscan en estos "atractivos turísticos" nuevos referentes de la santanderianidad, en un interés por potenciar aquellos elementos más atractivos para obtener la mayor rentabilidad económica posible (Martínez, 2006).

Gracias a esto, es cada día más popular la idea de que no es suficiente el reconocimiento oficial de una manifestación o bien cultural como patrimonio. Permitiendo entender que el patrimonio cultural debe ser siempre sometido a procesos de activación (Prats, 1997) y restauración del vínculo afectivo que lo liga a los usuarios. Algo similar sucede en el caso de disciplinas como la antropología y la historia. Las nuevas tendencias de la historia se encuentran mucho más preocupadas por las historias locales y la historia social, lo cual exige nuevas formas de conceptualizar el patrimonio y de entender las relaciones entre éste y nuestro pasado. 
Como consecuencia de este tipo de movimiento, los componentes que tradicionalmente se emplean para caracterizar nuestro patrimonio son cuestionados y, a menudo, considerados insuficientes, mientras el interés se desplaza hacia nuevos elementos, como ocurre con sus componentes simbólicos y subjetivos. Circunstancia que exige, en cierta medida, recuperar la memoria como componente vital en la gestión del patrimonio y en su valoración.

Gracias a estos cambios el patrimonio cultural se manifiesta como una realidad más próxima al concepto antropológico de cultura, y exige nuevas modalidades de gestión que permitan superar esta condición que lo condena a ser simple historia o conmemoración de nuestro pasado (Bolivar, 1999). Sin embargo, memoria e historia mantienen una relación diferente con el pasado, exigiendo que toda experiencia que persigue hacer de la memoria un sustento para el conocimiento del pasado, deba considerar estas diferencias; en el caso de la actual investigación son precisamente estas diferencias las que sustentan la elección de la historia oral escolar.

\section{Patrimonio e historia oral escolar}

Los historiadores suelen quejarse del desinterés que existe en la actualidad por las sociedades del pasado, por sus formas de vida y los conflictos entre las distintas clases y grupos sociales. En este aparente desinterés por la historia parece diluirse también nuestro conocimiento sobre el patrimonio cultural y su vínculo con la historia patria. Ciertamente, esta situación no resulta tan lamentable para todos los historiadores. Por mi parte, considero útil indagar en los lugares donde se alimenta nuestra memoria, en la historia personal, la cartografía social y, especialmente, en sus símbolos, para reconstruir nuestro vínculo afectivo con el patrimonio y su relación con la "historia" de la ciudad. Por tal motivo, la asociación entre historia oral escolar y educación patrimonial no es circunstancial y obedece a diversos aspectos.

Por un lado, la historia oral escolar posee diversas características que la convierten en una estrategia útil para aproximar a los estudiantes a la historia de la ciudad y a sus escenarios, a partir de las experiencias compar- tidas por sus habitantes. Por otro, permite acceder a la memoria individual y colectiva, aspectos cruciales si recordamos que la memoria, según explica Roger Chartier (2007), mantiene presente el pasado en una forma más poderosa de la que consiguen los libros de historia (y en nuestro caso, los monumentos y estatuas conmemorativas).

En resumen, se trata de una estrategia de enseñanza activa, donde se compromete a los estudiantes en el proceso de investigación y construcción de conocimiento histórico acerca del patrimonio cultural de sus comunidades y barrios, salvando de esta forma lo que Thad Sitton y George Mehaffy (en Historia oral: Una guía para profesores (y otras personas)), citados por Vega y Castaño (1999), denominan la brecha entre lo académico y la comunidad; lo cual supone una mejora sustantiva en los procesos actuales de educación patrimonial.

Lamentablemente, la oralidad se ha considerado algo específico de ciertas colectividades humanas, hecho que ha dejado como resultado, por un lado, una escasez de investigaciones que puedan identificar las estrategias y posibilidades ofrecidas por la historia oral escolar en la enseñanza patrimonial dentro de la ciudad, y por otro, otras investigaciones que permitan extender sus aplicaciones a nuevos horizontes; esto se debe a su confinamiento como estrategia educativa exclusiva para la etnoeducación.

Si se diera el caso contrario, sería posible que al seleccionar la investigación con fuente oral como proyecto educativo en la ciudad, su mediación permita el acceso y acercamiento a las fuentes y datos de su historia, conocimiento que se enriquece desde la experiencia y está ambientado en la vida cotidiana. A la vez facilitaría el análisis de sucesos históricos partiendo de lo local y la conexión entre la enseñanza de la historia con el entorno próximo de los estudiantes, en contacto directo con el paisaje cotidiano, convirtiéndolo, según la fórmula de Antonio Bardabio y Paloma (2003), en laboratorio para la enseñanza, a la vez que, como lo presenta Silvia Alderoquín (1996), en ciudad museo.

Aspecto importante, considerando que la verdadera educación patrimonial supone restaurar estos vínculos afectivos perdidos u olvidados en el tiempo. Especialmente, 

debido a que el concepto mismo de patrimonio cultural se encuentra vinculado estrechamente con la historia regional y de la ciudad. Sin embargo, la investigación sobre el tema en Colombia se centra en explorar el valor educativo y el uso didáctico del patrimonio cultural para la enseñanza de las ciencias sociales, y muy poco en aportar elementos que permitan asumir la educación patrimonial desde el aula de clase; esto sugiere al menos una primera revisión de la bibliografía existente (Rueda, 2013). Con esto en mente, en 2012 se realizó un proyecto de investigación con historia oral escolar.

\section{Metodología}

Esta investigación es de corte cualitativo y correspondiente a sus objetivos, se reconoce fácilmente dentro de un paradigma interpretativo de investigación, centrado en el pensamiento del profesor y los estudiantes (Kröll, 2004) o estudio de caso. Fue desarrollada en 5 fases, conformadas por etapas que sirven para la caracterización de la población, la recolección y preparación de los datos para el análisis, y el análisis e interpretación de los resultados, según la siguiente figura:

Figura 2. Diseño metodológico

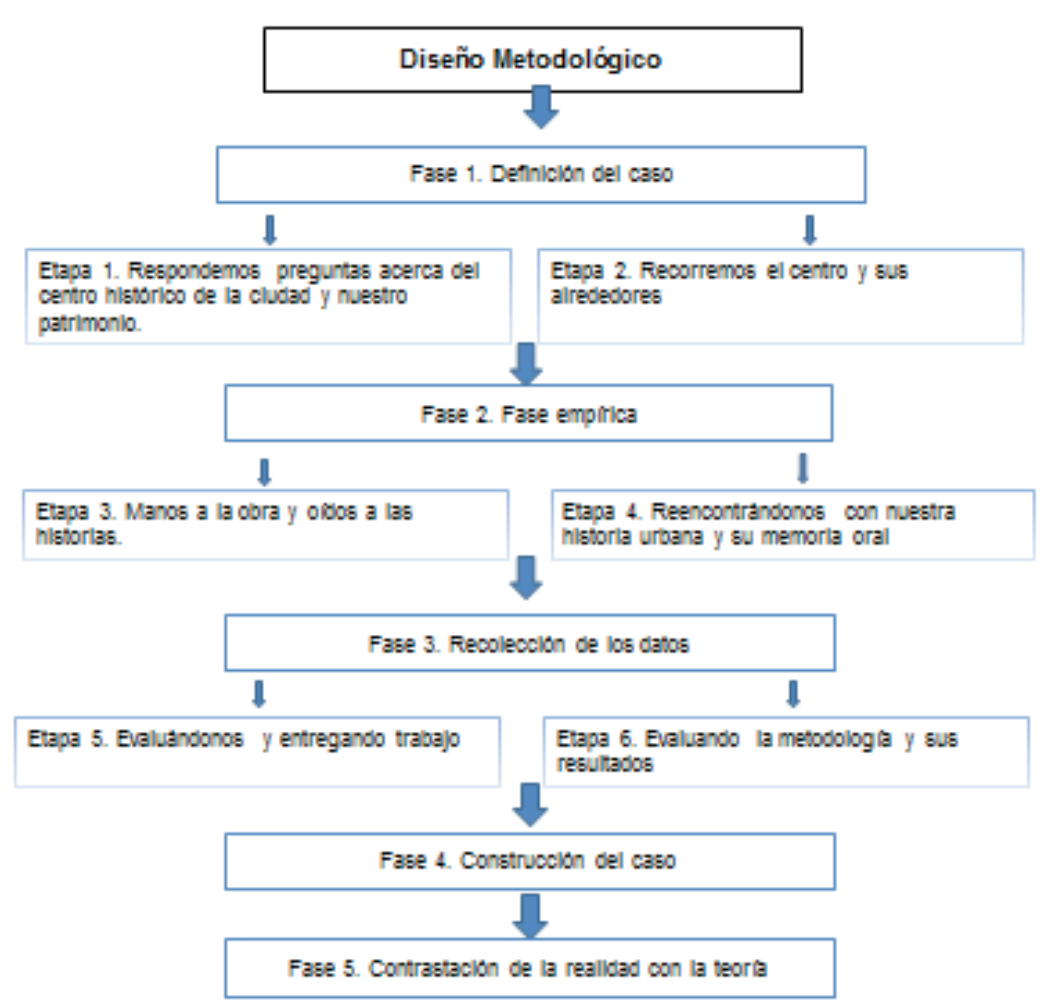

Los diarios de campo periódicos, elaborados para el registro de las actividades realizadas en el trascurso de las diferentes experiencias formativas, y durante las acciones propiamente investigativas como la aplicación de cuestionarios, constituyen el material de análisis, así como los trabajos entregados por los estudiantes y las experiencias al respecto (representadas por sus respuestas a los diferentes cuestionarios).

La población participante de esta investigación la constituyen los estudiantes de la asignatura Antropología en la cultura, el docente investigador y los habitantes del centro histórico de la ciudad, muchos de los cuales participaron como informantes en las entrevistas aplicadas por los estudiantes, a todos ellos muchas gracias por su participación.

\section{Población y caracterización}

La investigación inició la semana comprendida entre el 30 de Enero y 3 de febrero del 2012 (segunda y tercera semana de clase). Primero se establecieron algunos de los conocimientos de los estudiantes sobre el tema de 
patrimonio cultural y sus principales manifestaciones en la ciudad, esta información se obtuvo con ayuda de un cuestionario elaborado para tal propósito. Fue contestado por 118 estudiantes, distribuidos entre cuatro grupos de la asignatura "Antropología en la cultural". Posteriormente, se analizaron sus respuestas para conocer el punto de partida desde el cual se pone en marcha la experiencia con la historia oral escolar y sus resultados (principalmente, por representar esta una falencia identificada en investigaciones anteriores).

El concepto de patrimonio cultural se encuentra vinculado en las repuestas de los estudiantes a otras nociones que se pueden considerar sinónimos del mismo: 1) Patrimonio histórico (patrimonium, connotación jurídica donde se reconoce su importancia como legado o herencia de las generaciones anteriores); 2) Tesoros nacionales (donde se reconoce su importancia como representación de nuestra identidad y origen en el marco de la pedagogía del Estado-nacion) y, 3) Como monumentos o bienes de interés cultural, por su valor arquitectónico o artístico.

Las respuestas de los estudiantes permitieron conocer, además, diversos ejemplos de manifestaciones culturales que según ellos conforman nuestro patrimonio cultural e incluso, a veces, sus ejemplos se extienden a todo Santander. Sin embargo, es claro que muchos de los escenarios considerados por los estudiantes como patrimonio cultural, se encuentran ubicados cerca del centro histórico de Bucaramanga, en total 22. Los escenarios más comunes en sus respuestas fueron parques, iglesias y lugares de la ciudad destinados a actividades culturales, como museos, bibliotecas y algunos "monumentos", como el "Caballo de Bolívar" (frente a la UIS y sobre la Cra. 27) y "La Gorda de Botero" (escultura titulada originalmente "Mujer de pie Desnuda", del maestro Fernando Botero).

Por otro lado, existe un consenso general acerca de la importancia del patrimonio cultural y, sin embargo, como sugiere Olaia Fontal (2003), este consenso desaparece cuando se trata de inventariarlo, de delimitarlo e incluso de identificarlo. Situación que, como mostraremos más adelante, la implementación de la historia de oral escolar permite superar.

\section{Resultados}

\section{Salidas pedagógicas: El centro de Bucaramanga y} sus alrededores

Los recorridos por el centro de la ciudad y sus alrededores se realizaron con algunos estudiantes durante los fines de semana del 25 de Febrero y el tres de Marzo de 2012, semanas 5 y 6 después de iniciado el semestre académico. El objetivo principal de estas salidas pedagógicas fue propiciar el acercamiento e incluso el reencuentro de los estudiantes con el centro histórico de la ciudad y sus habitantes; se realizaron recorridos guiados y circuitos de observación, donde se les invitaba a registrar diferentes aspectos del patrimonio monumental y arquitectónico de la ciudad.

Durante esta experiencia, el encuentro con los escenarios y el patrimonio cultural se dio mediado por actividades e instrumentos. Se proporcionó a los grupos de trabajo unas guías de observación y además se compartieron diversas experiencias formativas en torno a nuestro patrimonio cultural. El uso de instrumentos de registro era importante, pues representan, como tal, una ayuda en el proceso de reunir y organizar adecuadamente la información procedente de sus experiencias. Su importancia era, por tal motivo, siguiendo la recomendación de Bernie Dodge, y entendiendo el concepto en términos de Jordi Adell (2004), servir como "andamios de recepción".

Los estudiantes debían comentar más tarde sus experiencias durante su permanencia en el centro e incluir una breve descripción de los motivos que tenían para considerar estos escenarios como manifestaciones de patrimonio cultural. Para precisar su ubicación y evitar confusiones, fue necesario establecer primero las calles y carreras que comprenden actualmente el centro de la ciudad (desde la Carrera Novena y la Carrera 27, hasta el sector de la Avenida Quebrada Seca y la Avenida La Rosita). Fueron, así, comunes los trabajos realizados en sectores como el parque García Rovira (centro histórico de la ciudad) y sus alrededores; también, entre otros, los parques de Santander y Bolívar, considerados patrimonio por sus monumentos (estatuas del Libertador 
Simón Bolívar, Santander u otros próceres, ubicadas, por lo general en el centro del parque), posiblemente porque son punto de encuentro y de descanso en el recorrido propuesto.

Fuera de estos lugares se destacan, además, escenarios culturales (museos y casa de cultura), iglesias y parques de la ciudad como lugares especialmente visitados por los estudiantes. Para el caso de las iglesias las descripciones incluyen a menudo comentarios sobre las características estéticas, arquitectónicas e históricas de estos lugares. Mientras que para el caso de los parques son mucho más comunes los comentarios que evalúan la presencia o ausencia de seguridad y las condiciones para garantizar la comodidad de los visitantes. Desde luego, la antigüedad de estos escenarios es a menudo un elemento importante para orientar su elección y también es un aspecto referido permanentemente por los estudiantes en sus comentarios. Se realizaron en total dos recorridos guiados y colectivos (fuera de los realizados en tiempos y momentos distintos por los demás estudiantes).

Con esta actividad no solamente se propició el acercamiento de los estudiantes a los lugares del centro, sino que fue útil como incentivo para el diálogo con sus habitantes cotidianos. De manera que, en ciertas ocasiones, los estudiantes se animaron a preguntar a las personas que frecuentan estos lugares por el nombre e historia de alguno de los próceres representados en los monumentos. Muchos realizaron, junto al registro de sus observaciones, entrevistas a las personas que se encuentran en estos lugares (comerciantes y visitantes casuales del centro). Además, en ocasiones sus trabajos se complementan con la consulta de fuentes escritas sobre la historia y con referencias a los acontecimientos importantes ocurridos en estos escenarios.

Confrontar y sensibilizar a los estudiantes con las condiciones actuales en que se encuentra el patrimonio cultural de la ciudad, fue un logro importante de la experiencia. Confirmación de esto fueron las críticas y manifestaciones de rechazo a la lamentable condición de algunos de los lugares considerados como patrimonio, fue este un tema recurrente en sus reflexiones. Sus críticas se refieren especialmente a los parques y calles del centro. Para los parques se critica la mendicidad, la inseguridad y las condiciones de aseo (basuras y falta de cuidado general). Para otros lugares del centro, señalaron esencialmente la congestión ocasionada por el comercio formal e informal; éste último, caracterizado por un alto número de vendedores ambulantes y sus actividades, lo cual para algunos estudiantes "afecta un ambiente de paz y tranquilidad".

Manos a la obra y oídos a las historias: Patrimonio e historia oral escolar

La recolección de las historias de vida fue realizada por los estudiantes entre las semanas del 9 y el 30 de abril del 2012, semana 13 a 16 del semestre académico. Para tal actividad se conformaron grupos de trabajo y se desarrollaron algunas actividades complementarias; especificando, por ejemplo, las características que debían tener sus informantes y las condiciones de recolección de las historias de vida, que exigían, entre otras cosas, la presentación de un registro en audio o video como evidencia.

Como resultado final de este proceso, los estudiantes, en grupos, debían elaborar una guía turística o folleto similar a los que entregan diferentes hoteles y entidades culturales de la ciudad, y que en nuestro caso sirvieran para orientar a las personas en un recorrido por el patrimonio arquitectónico y monumental del centro. Este folleto debería aclarar quiénes habían sido sus informantes y los sitios de interés que recomendaban visitar, acompañados de una breve reseña y su ubicación en la ruta propuestas. La procedencia de las historias de vida recolectadas y las características de los informantes elegidos por los estudiantes, se presentan a continuación:

Cuadro1. Los informantes

\begin{tabular}{|c|c|}
\hline Informantes Historias de Vida & $\begin{array}{c}\text { No. de } \\
\text { Informantes }\end{array}$ \\
\hline $\begin{array}{c}\text { Residentes del centro } \\
\text { y sus alrededores }\end{array}$ & 26 \\
\hline $\begin{array}{c}\text { Comerciantes y empresarios con } \\
\text { lugar de trabajo en el centro }\end{array}$ & 9 \\
\hline $\begin{array}{c}\text { Expertos: Gestores culturales, } \\
\text { periodistas y guías de museos }\end{array}$ & 5 \\
\hline Otros & 1 \\
\hline
\end{tabular}


El objetivo perseguido con la implementación de la historia oral escolar, era restaurar el vínculo del patrimonio cultural con temas cotidianos e historias de vida, promoviendo así el desarrollo de la conciencia patrimonial en los estudiantes. Como resultado, algunos estudiantes fueron capaces de comprender que las manifestaciones de patrimonio cultural cambian en el tiempo y que, en ciertos casos, el patrimonio cultural que desaparece o se encuentra en proceso de desaparición, mantiene su vigencia para ciertas personas, por ser referente de su identidad y por guardar recuerdos que forman parte de sus experiencias de vida y de las vivencias compartidas por un grupo social.

La recolección de historias de vida permitió, además, que muchos de los estudiantes asociaran escenarios y lugares considerados patrimonio cultural, a las historias de acontecimientos y experiencias relatadas por sus informantes. De manera que la historia oral escolar no resultó únicamente útil para ampliar sus conocimientos acerca del patrimonio cultural, fue, además, una manera de restaurar el vínculo entre estos escenarios y la historia regional; también fue útil para comprender que los lugares del centro guardan "gran historia" y que ésta incide en la vida de los informantes o sirve como referente en la construcción de nuestra identidad.

Al respecto, gracias a los relatos de estos informantes se pudo rescatar del olvido muchos escenarios culturales del pasado, actualmente desaparecidos o en proceso de desaparecer (como el Teatro Sotomayor, en la Calle 37 con Carrera 27, y el Teatro Libertador, en la Carrera 15 , entre 22 y 23 ).

\section{Conclusiones}

Conocer la historia de la ciudad y la del centro, su cultura y costumbres del pasado, sus cambios materiales y las transformaciones que han ocurrido con el transcurso del tiempo, son algunos de los aprendizajes que fueron posibles gracias a la historia de vida escolar y de las experiencias con el patrimonio cultural, según afirman los estudiantes. La historia oral escolar sirve, en este caso, para revestir de experiencias y significados personales el carácter abstracto del cual lo dota la normatividad y la literatura existente sobre el tema, motivando a menudo cambios de actitud respecto del centro y sus escenarios. Esto confirma las conclusiones de Sitton (1989), para quien, si bien es cierto que la comprensión de la historia es en parte cognoscitiva, su enseñanza exige también una comprensión afectiva.

En cuanto a los nuevos hallazgos identificados como resultado de esta investigación, se destaca la utilidad de la historia de vida escolar como una manera de recuperar la memoria perdida y, en nuestro caso, el recuerdo de escenarios históricos que desaparecen en la ciudad, renovados o demolidos con el pasar de los años, así ocurre con varios de los antiguos teatros (Cerca de la 15, teatros que funcionaron en Bucaramanga como salas de cine desde los años 40, y se fueron acabando uno tras otro. Hoy no sobrevive ninguno. Los últimos en cerrarse fueron el Riviera y el Rosedal, en 2009). Aspecto que también se evidencia con la aparición de nuevos escenarios en los diferentes momentos de la investigación y en los trabajos finales; 12 nuevos escenarios fueron identificados en el centro.

La comparación de las respuestas frente a diversos temas en el primer cuestionario, y los resultados presentados en los trabajos finales, permite afirmar que gracias a la historia oral existe una idea más clara de las relaciones que vinculan el patrimonio cultural con la historia de la ciudad y la identidad de los colectivos sociales. Por lo cual, la experiencia fue importante, ya que ofreció la oportunidad de confrontar las definiciones e ideas iníciales con la realidad y permitió crear nuevos conceptos ligados a las experiencias personales y la historia de la ciudad.

Vincular el patrimonio cultural a la historia de vida de los informantes es un ejercicio fundamental para entender que estas construcciones no son únicamente el legado de una época pasada o de un momento concreto en la historia, sino que son escenarios donde se desarroIla la vida de la ciudad y de sus habitantes. La historia oral escolar se convierte así en una alternativa útil para propiciar el interrogante por la propia memoria y por la manera como se desearía trasmitirla y compartirla, origen de la imaginación autobiográfica (Feixa, 2003). Así, el patrimonio se convierte en una herramienta de comunicación entre las personas, para, según la fórmula propuesta por Yves Hanosset (González-Monfort, 2008), descubrir quién soy y quiénes son los otros. 
Acuña, A. (2010). La enseñanza de la historia desde las experiencias de vida. Una propuesta pedagógica en construcción. Ponencia no publicada. Memorias del IX Congreso Internacional de la Asociación de Historiadores Latinoamericanos y del Caribe (ADHILAC). Santa Marta.

Adell, J. (2004). Internet en el aula: las WebQuest. Edutec, Revista electrónica de tecnología educativa. No. 17. Recuperado el 12 de Agosto de 2012, desde http://www.cyta.com.ar/elearn/wq/ wq_archivos/AdellWQ.pdf

Alderoquin, S. (Comp.) (1996). Museo y escuela: socios para educar. Buenos aires: Paidós Ibérica.

Bardabio, A. y Gonzáles, P. (2003). Objetos en el tiempo. Las fuentes materiales de la historia. Barcelona: Horsori.

Betancourt, D. (2006). Memoria individual, memoria colectiva y memoria histórica. Lo secreto y lo escondido en la narración y el recuerdo. En Jiménez, A. y Torres, A. (Comp.). La práctica investigativa en ciencias sociales. (pp. 125 -157). Obtenido el 20 de febrero de 2007, desde http://institucional.us.es/revistas/ revistas/cuestiones/pdf/numeros/19/12 Monteagudo.pdf

Bolívar, E. (1999). Patrimonio cultural. Algo más que objetos, algo más que pasado. Revista Territorio, 2. Medellín: Secretaría de educación y cultura de Antioquia, pp. 3-17.

Certeau, M. y Lucen, G. (1999). Los aparecidos de la ciudad. En Certeau, M. y Lucen, G., et al. La invención de lo cotidiano 2. Habitar, cocinar. (pp. 135-146). México: Universidad Iberoamericana.

Chartier, R. (2007). La historia o la lectura del tiempo. Barcelona: Gedisa.

Corradini, L. (2006, 15 de marzo). "No hay que confundir memoria con historia", dijo Pierre Nora. La Nación. Obtenido el 27 de Julio de 2012, desde http://www. lanacion.com.ar/788817no-hay-que-confundir-memoria-con-historia-dijo-pierre-nora

Díaz, L. (2008, mayo). La gente crea constantemente palabras y relatos para contarse el mundo. $Y$ vale la pena ocuparse de ello. Entrevista realizada por Juan Ignacio Pérez. Web LitOral, asociación para la difusión de la literatura oral. Obtenido el 23 de septiembre de 2012, desde http://weblitoral.com/entrevistas/ investigadores/luis-diaz-viana

Fernández, M. (2008). La utilización del patrimonio como recurso didáctico en la enseñanza secundaria, al tiempo que como vía de conocimiento y valoración del mismo. En Xerardo, S., e Hiroco, T. (Coord.). Patrimonios culturales: educación e interpretación, cruzando límites y produciendo alternativas. Memorias del XI Congreso de Antropología: Retos teóricos y nuevas prácticas, Donostia, San Sebastián, 10-13 de septiembre de 2008. Obtenido el 12 de febrero de 2012, desde http://www.ankulegi.org/wpcontent/ uploads/2012/03/1206Fernandez-Casildo.pdf

Feixa, C. (2003, mayo). La imaginación autobiográfica. Revista Nómadas. 18. Bogotá: Universidad Central.

Fontal, O. (2003). La educación patrimonial. Teoría y práctica en el aula, el museo e internet. Asturias: Ediciones TREA.
González-Monfort, N. (2008). Una investigación cualitativa y etnográfica sobre el valor educativo y el uso didáctico del patrimonio cultural. Revista Enseñanza de las ciencias sociales, 7. Barcelona: Universitat de Barcelona. Obtenido el 10 de diciembre de 2013, desde Redalyc.org, Red de Revistas Científicas de América Latina y el Caribe, España y Portugal, pp. 23-36.

Jaillier, E. (2003). Comunicación, investigación y ciudad. MedeIlín: Universidad Pontificia Bolivariana.

Köll, H. (2004). El método de los estudios de caso. En Tarrés, M. L. Observar, escuchar y comprender: sobre la tradición cualitativa en la investigación social. No. 1. México: Porrúa, pp. 251- 282.

Martínez, A. (2006). Los nuevos monumentos de la santanderianidad. Revista de Santander. No. 1. Bucaramanga: Universidad Industrial de Santander, pp. 20 -39.

Martínez, S. (2009). El imaginario civilista en los parques del centro de Bucaramanga. Revista de Santander. No. 4. Bucaramanga: Universidad Industrial de Santander, pp. 44-65.

Medina, F. (2003). Comunicación consumo y ciudad. Medellín: Universidad Pontificia Bolivariana.

Meirieu, P. (1998). Frankenstein Educador. Barcelona: Laertes.

Prats, L. (1997). Patrimonio y antropología. Barcelona: Ariel.

Reguillo, R. (2006). Los miedos contemporáneos: sus laberintos, sus monstruos y sus conjuros. En Villadiego, M. y Pereira, M. (Eds.). Entre miedos y goces: comunicación, vida pública y ciudadanías. (pp. 25- 55). Bogotá: Pontificia Universidad Javeriana.

Reguillo, R. (2008, julio-diciembre). Sociabilidad, inseguridad y miedos. Una trilogía para pensar la ciudad contemporánea. Alteridades, 18 (36), pp. 63-74.

Rueda, O. (2013). La historia oral escolar: estrategia para promover el reencuentro, valoración y conocimiento del patrimonio cultural urbano entre jóvenes universitarios. Un estudio de caso. Tesis de grado no publicada. Bucaramanga: Universidad Industrial de Santander.

Santiago, H. (1996). Didáctica de la historia, una propuesta desde la pedagogía activa. Bogotá: Cooperativa Editorial Magisterio.

Suarez, H. y Valencia, A. (Comp. Ed.). (1995). Educación y democracia: un campo de combate. Bogotá: Fundación Estanislao Zuleta.

Vargas, S., Acosta, M. y Sánchez, R. (2013). Historia, memoria, pedagogía: una propuesta alternativa de enseñanza-aprendizaje de la historia. Bogotá: Corporación Universitaria Minuto de Dios. Facultad de Educación.

Vega, R. y Castaño, R. (Comp.). (1999). ¡Déjenos hablar! Profesores y estudiantes tejen historias orales en el espacio escolar. Bogotá: Universidad Pedagógica Nacional. 


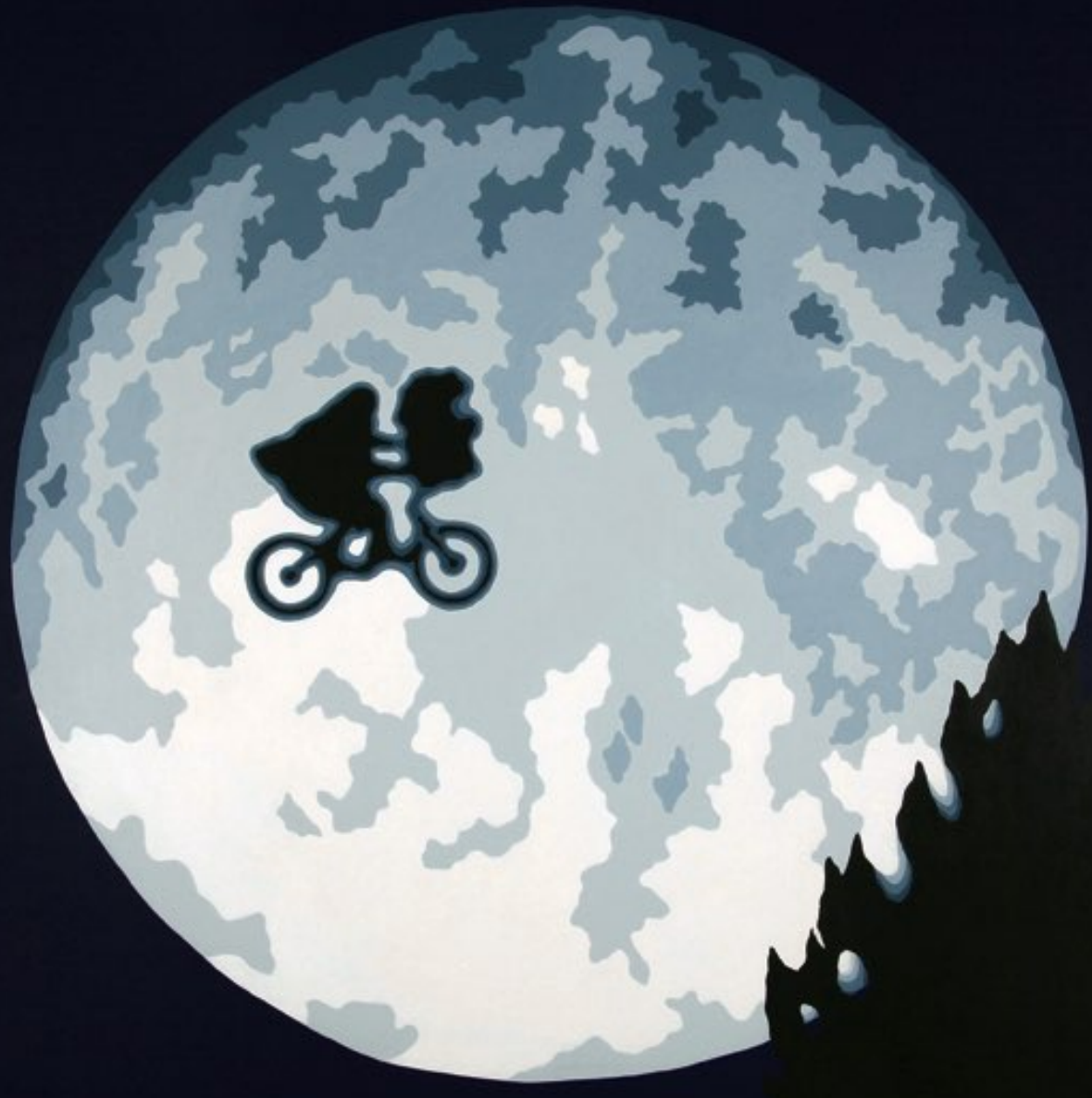

Franklin Aguirre ॥ Título: Recuerdo Profundo 2 ॥ Técnica: Acrílico sobre lienzo ॥ Tamaño: 100 X 175 cm ॥ Año: 2006 


\section{Diálogo del conocimiento}

En la perspectiva del conocimiento y apropiación del patrimonio cultural como relación, práctica, urdimbre de expresiones culturales vivas, experiencia significativa, dinámica y cambiante; el autor nos propone nuevos derroteros conceptuales y nuevos escenarios, que trasciendan las viejas formas educativas dadas en la relación con el conocimiento y los aprendizajes, desde las culturas institucionales caracterizadas por las rígidas relaciones y formalizaciones: profesor-alumno, texto-contenido, aula de clase-enseñanza.

Por ello, desde su investigación explora un nuevo sentido, nuevas posibilidades, búsquedas alternativas de construcción y apropiación de un nuevo sentido del patrimonio cultural y, desde él, proponer y propiciar en la educación nuevas relaciones, producciones de sentido y producciones de presencia, dadas las diversas manifestaciones culturales, la diferenciación y particularidades de los contextos sociales.

Desde estos aspectos, los propósitos son trascender el relato oficial dominante institucional que -en términos de Estanislao Zuleta, como lo señala el autor- se constituye en "Leyenda Patria" ajena a todo tipo de interrogantes, matices, visones críticas y prospectivas.

Este descentramiento del hecho educativo actual, de las prácticas pedagógicas, conlleva una nueva mirada de sujeto, de ciudad y de educación en la comprensión y apropiación del patrimonio cultural.

Por ejemplo, la ciudad como espacio que habitamos propios y extraños, nos interpela por asuntos como las costumbres, los rituales, las celebraciones, las comunidades y sus nexos, los hechos históricos y la conciencia sobre el mismo, así aaaaasssss, así como por su ser y acontecer.

Desde la ciudad y la escuela, dentro de las nuevas formas de apropiación del patrimonio cultural emergen redes y practicas de identidad, de vinculación, de filiación y afiliación en ese entramado de procesos de construcción de identidades, lo cual implica, según el autor: "restaurar el significado social del patrimonio", dando peso específico y equilibrando las políticas, las prácticas, los códigos culturales, las formas de apropiación y la conciencia sobre el mismo, desde una perspectiva cultural amplia donde la escuela juegue un rol dinámico y autónomo.

Donde la resolución de las ausencias, las omisiones y los silencios, logre poner en un régimen de visibilidad, legitimidad y conectividad inclusiva y democrática lo formal, lo enunciativo, declarativo, normativo que contienen las políticas institucionales, en apertura a procesos alternativos instituyentes donde se resuelvan las fracturas que los ciudadanos, que los alumnos tienen frente a las precariedades y sin sentidos de las prácticas y experiencias del presente, en la perspectiva de imaginarios y futuros, como nuevas apuestas de construcción simbólica, de nuevas subjetividades y de construcción de memoria.

Órinzon Perdomo Guerrero 